\author{
Н.В. Срмілова ${ }^{1}$, Є.В. Гаврилко ${ }^{2}$, С.Г. Кислиця ${ }^{1}$ \\ ${ }^{1}$ Полтавський національний технічний університет імені Юрія Кондратюка, Полтава \\ ${ }^{2}$ Державний університет телекомунікаиій, Київ
}

\title{
МОДЕЛЮВАННЯ ТА ДОСЛІДЖЕННЯ ЕЛЕКТРОПРИВОДА ПОВОРОТНОЇ ПЛАТФОРМИ ОДНОКІВШЕВИХ ЕКСКАВАТОРІВ
}

У статті розглянуто сучасний стан і напрямки розвитку електроприводу механізму повороту одноківиевих екскаваторів. Розроблені комп ютерні моделі систем автоматичного керування для двох випадків: без урахування та з урахуванням пружних властивостей об'єкту. Проведене моделювання системи дало змогу проаналізувати динамічні властивості електроприводу екскаватора разом з його механічною частиною та отримати висновки про шляхи досягнення найкращьӧ динаміки системи.

Ключові слова: електропривод екскаватора, поворотна платформа, пружність системи, комп'ютерна модель, автоматичне керування.

\section{Вступ}

В роботі розглядається електропривод одноківшевого кар'єрного екскаватора, якій широко застосовується на відкритих гірничих розробках з видобутку корисних копалин. Механізм повороту такого екскаватора повинен забезпечувати пряме (розвантаження) і поворотне обертання платформи. 3 метою зниження витрат часу на поворотні рухи, які складають значну частину тривалості робочого циклу, використовують режими прискореного розгону і гальмування.

До електроприводу механізму повороту додатковою вимогою є забезпечення плавності протікання перехідних процесів при відпрацюванні заданого кута повороту й мінімально можливий час повороту 3 обмеженим прискоренням. Це викликано тим, що механізм повороту має значний приведений момент інерції, який в декілька разів перевищує момент інерції двигуна. Крім того, внаслідок великого передаточного числа в передачі наявні значні люфти й зазори [1].

Привод повороту є найскладнішою частиною 3 огляду на вимоги до електроприводу екскаватора i дуже складним з точки зору реалізації цих вимог. Це пов'язано з тим, що електроустаткування екскаватора працює в важких умовах трясіння, ударів, вібрацій, великої запорошеності, в інтенсивних пуско-гальмівних режимах 3 великою частотою вмикань та змінному навантаженні [2]. Механічна частина приводу повороту має достатньо довгі вали, що створюють пружні зв'язки та значні люфти, які 3 часом лише зростають [3]. Дослідження цих явищ внаслідок складності електромеханічних процесів зі значними коливаннями є достатньо проблемним i без комп'ютерної техніки практично неможливим.

Мета роботи - створення комп'ютерних моделей системи автоматичного керування (САК) електропривода поворотної платформи з урахуванням i без урахування іiі пружності та аналіз на основі цих моделей динамічних властивостей системи електроприводу поворотної платформи одноківшевого екскаватора 3 метою визначення шляхів досягнення найкращої динаміки досліджуваної системи.

\section{Результати дослідження}

В процесі роботи був розроблений електропривод поворотної платформи одноківшевого екскаватору по системі «Тиристорний перетворювач - двигун постійного струму» на базі двох двигунів потужністю по 100 кВт, які з'єднані між собою валом. Кожен двигун живиться від власного тиристорного перетворювача. Система керування складається 3 чотирьох контурів: напруги, струму якоря, швидкості, положення. Крім того, в схемі керування реалізований зворотний зв'язок за пружним моментом, який заведений на регулятор струму. На регулятори струму обох систем подаються сигнали 3 пристрою вирівнювання навантажень.

На вході контуру регулювання швидкості встановлений задатчик інтенсивності, що буде забезпечувати обмеження ривку. Ця система повина відповідати сучасним вимогам, поставленим до електроприводу поворотної платформи одноківшевого екскаватору, для чого й було потрібно провести дослідження іiї параметрів.

Для рішення цієї задачі було розроблено структурні схеми контурів регулювання напруги, струму, швидкості та положення. Розраховані основні параметри схем. Також розроблено та розраховано структурні схеми задавачів ітенсивності першого та другого роду. На базі структурних схем розроблені комп'ютерні моделі контурів та загальна модель САК. bДинаміка електромеханічної системи була досліджена для двох випадків: без урахування пружних властивостей (рис. 1) та з урахуванням пружності об'єкту (розгалужена тримасова електромеханічна система). 


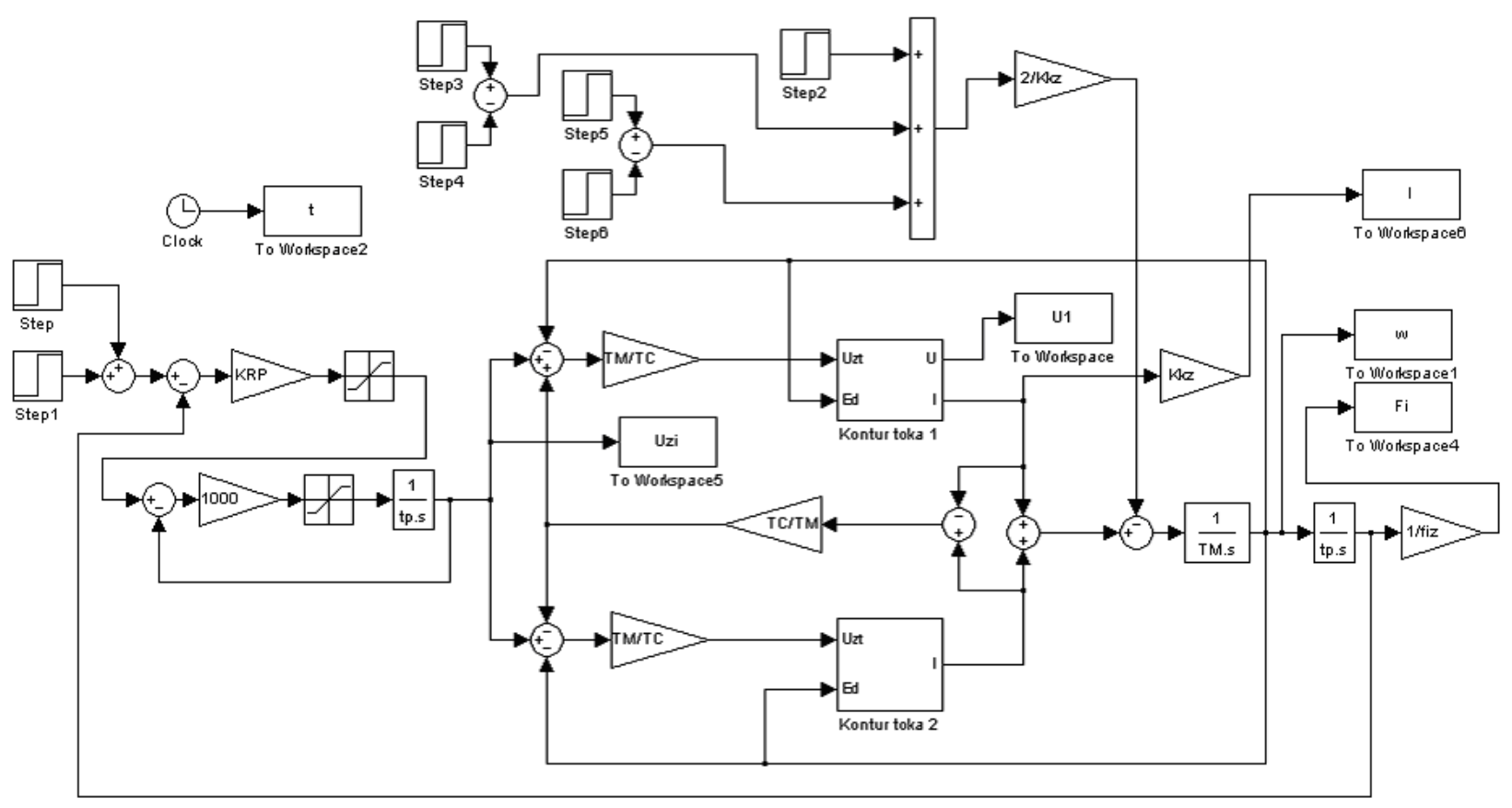

Рис. 1. Модель САК електропривода поворотної платформи екскаватора без урахування пружності

Для рішення поставленої задачі було використано додаток MATLAB Simulink. Для зручності зображення контур регулювання струму, у який вкладений контур регулювання напруги, представлений макроблоком. Кількість таких макроблоків відповідає кількості двигунів, тобто їх два. Сигнал струму I й сигнал напруги $\mathrm{U}_{1}$ знімається 3 першого макроблоку. Також в окремих вікнах виводяться сигнали швидкості $\mathrm{W}$ i положення $\mathrm{F}_{\mathrm{i}}$. Реєстрація вихідних сигналів здійснюється блоками To Workspace.

Були досліджені режими роботи системи, які відповідають режимам роботи механізму повороту одноківшевого екскаватора: поворот екскаватора у забій (розгін, рух зі сталою швидкістю і гальмування); робота екскаватора у забої; поворот екскаватора на розвантаження (розгін, рух зі сталою швидкістю і гальмування в зворотну сторону); розвантаження ковша (рис.1-4).

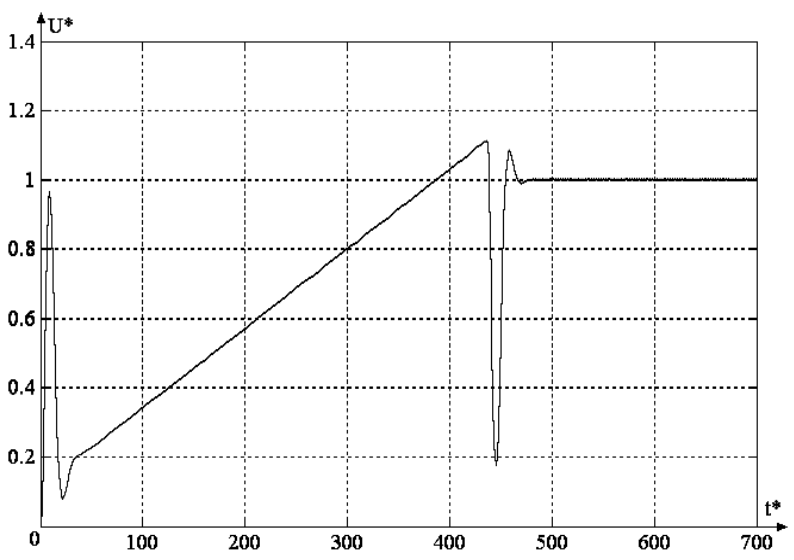

Рис. 2. Графік залежності напруги якоря U(t) від відносного часу при розгоні платформи без навантаження

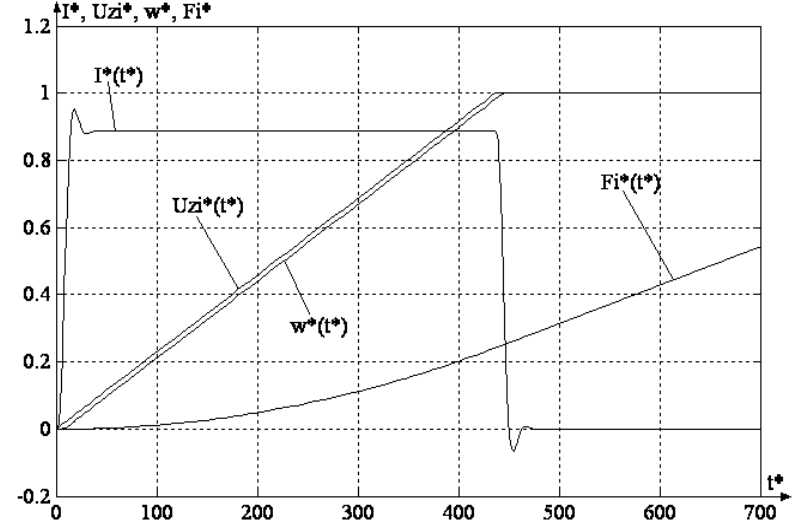

Рис. 3. Графіки залежностей I(t), UZI(t), W(t), Fi(t) при розгоні платформи без навантаження

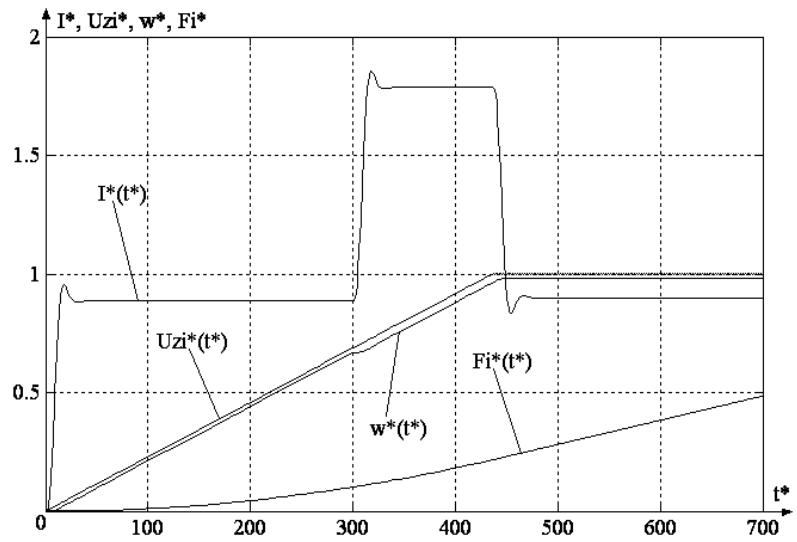

Рис. 4. Графіки залежностей: I(t), UZI(t), W(t), Fi(t) при розгоні платформи 3 навантаженням

Для одержання перехідних функцій контурів регулювання напруги, струму і швидкості використані відповідні моделі. Моделювання даної електромеханічної системи $з$ урахуванням пружності і зазо- 
рів проводилося аналогічно попередньому методу, але для проведення досліджень додатково був застосований блок механічної частини тримасової елект- ромеханічної системи (TEMS). Модель САК електропривода 3 урахуванням пружності системи приведена на рис. 5.

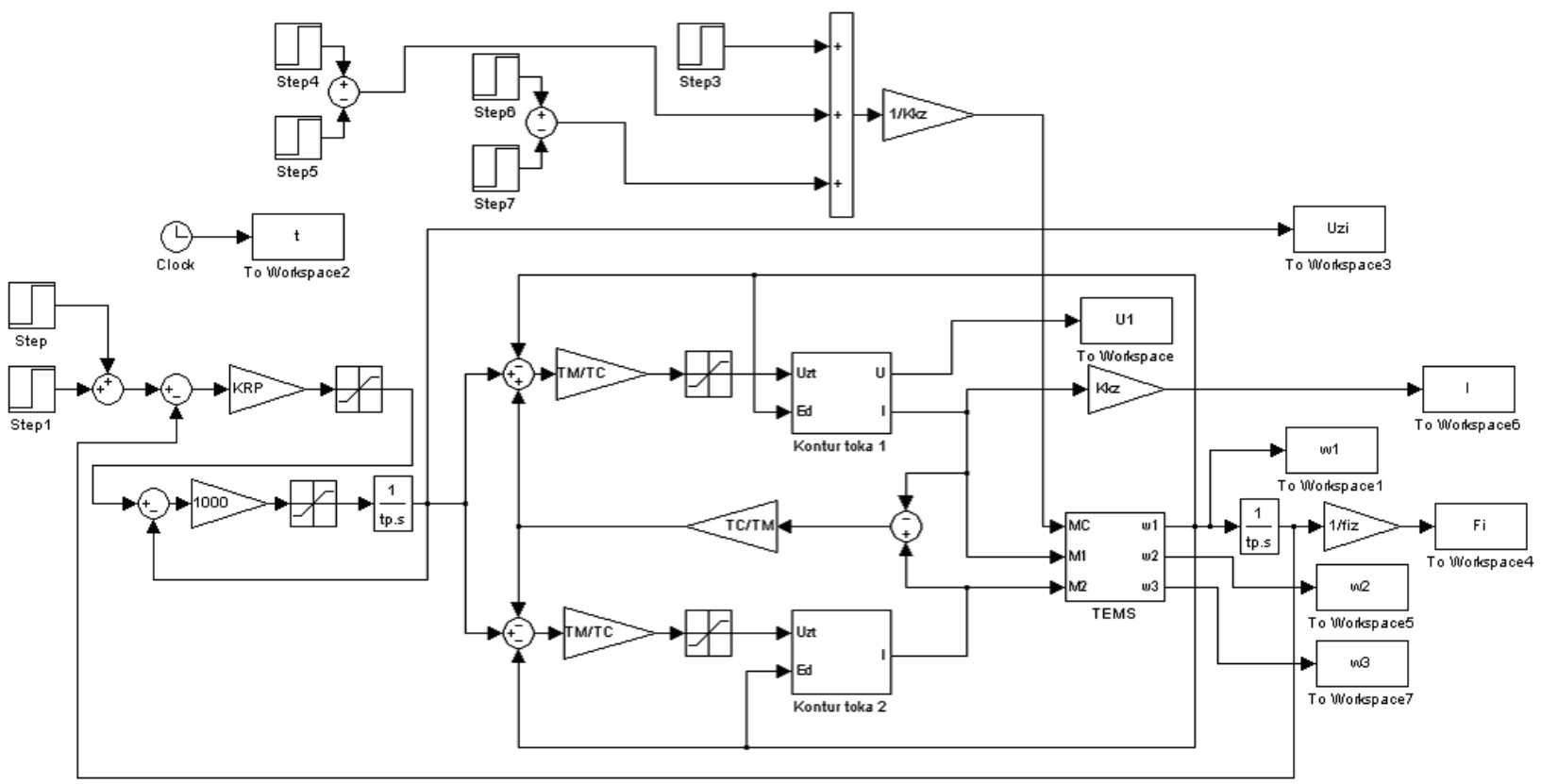

Рис. 5. Модель САК електропривода поворотної платформи екскаватора з урахуванням пружності

В процесі моделювання отримані графіки перехідних процесів в системі з задавачем інтенсивності першого та другого роду. При цьому було досліджено режими без регуляторів та 3 регуляторами напруги і пружного моменту [5].

Отримані графіки зображені на рис. 6-9.

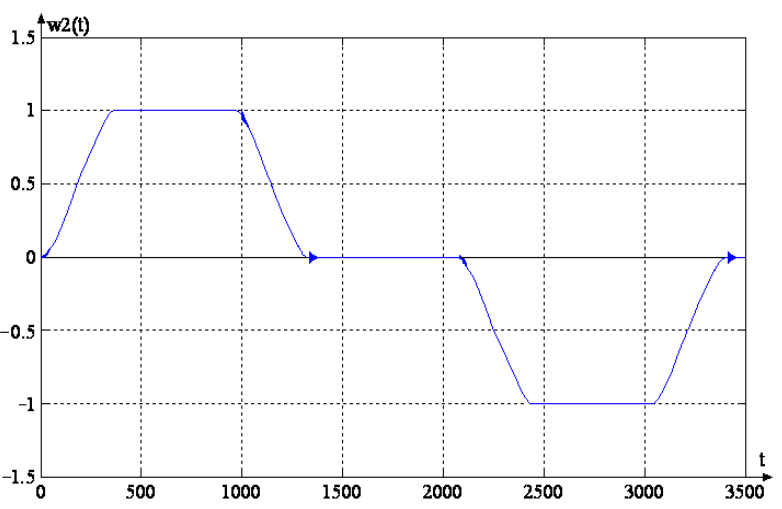

Рис. 6. Залежність швидкості першої маси від часу

Як можна побачити з графіків, при дослідженні швидкості другої маси з'являються невеликі перерегулювання.

В результаті проведених досліджень отримано такі результати:

- графіки перехідних процесів без врахування пружності та із задавачем інтенсивності першого роду не відображають коливань поворотної платформи екскаватора, при цьому швидкість двигуна відповідає завданню швидкості та має незначні від-

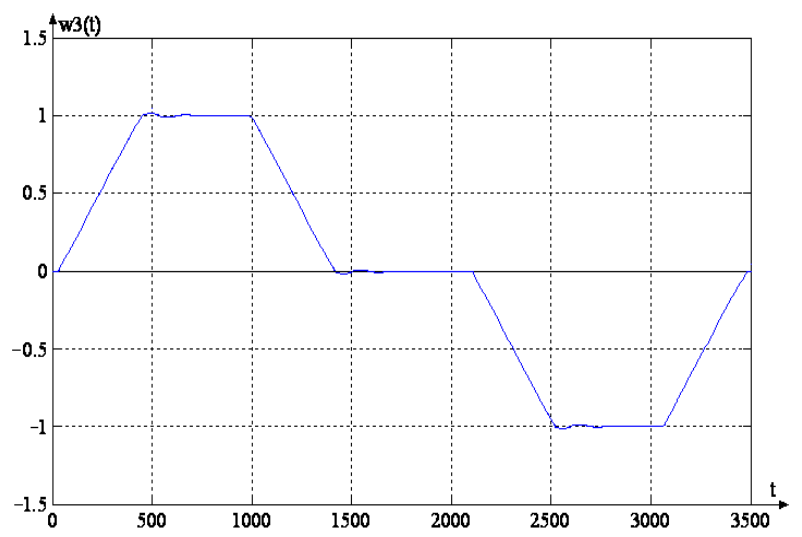

Рис. 7. Залежність швидкості другої маси від часу

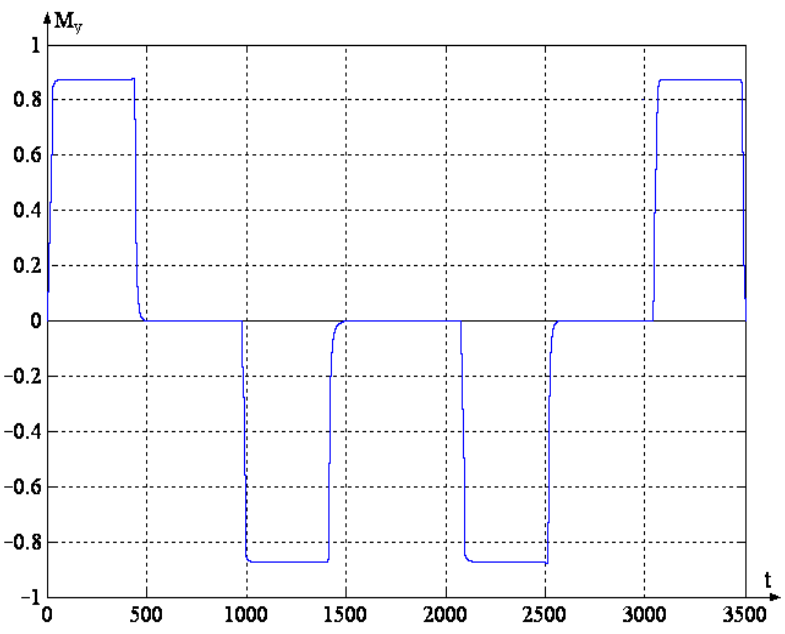

Рис. 8. Залежність пружного моменту від часу 


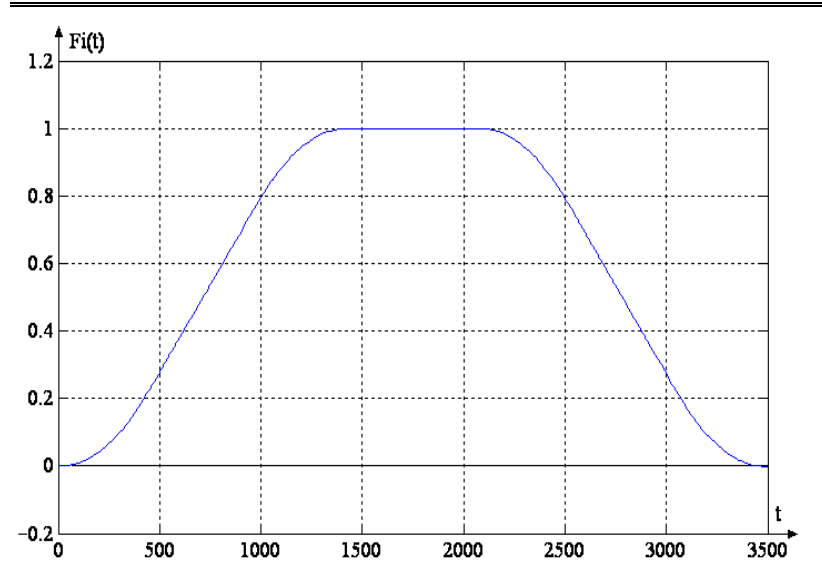

Рис. 9. Залежність кута положення від часу

хилення на ділянках навантаження. Перехідні процесі по струму мають невелике перерегулювання;

- графіки перехідних процесів 3 врахуванням пружності та задавачем інтенсивності першого роду відображають незначні коливання. Крім того, на характеристики впливають люфти, зазори й пружні зв'язки. Про це свідчить виникнення високочастотних коливань на перегинах швидкості другої маси. Ці коливання накладаються на коливання, викликані пружністю кінематичного ланцюга;

- при використанні задавача інтенсивності другого роду вдається добитися лінійної зміни прискорення (обмеження ривку);

- в системі без регулятора напруги спостерігалася найгірша динаміка (значні коливання); а в системі 3 регулятором напруги та при використанні регулятора пружного моменту вдалося отримати кращу динаміку, яка показує лише незначні коливання.

\section{Висновки}

Таким чином, розроблена комп'ютерна модель САК дводвигунного реверсивного тиристорного електроприводу постійного струму для поворотної платформи кар'єрного екскаватора дала змогу проаналізувати динамічні властивості електроприводу екскаватора разом 3 його механічною частиною.

Проведене математичне моделювання системи показало, що найкраща динаміка досягається при використанні чотириконтурної системи регулювання 3 використанням регулятора пружного моменту та задавачем інтенсивності другого роду.

\section{Список літератури}

1. Портной Т.З., Парфёнов Б.М., Коган А.И. Современное состояние и направления развития электротехнических комплексов одноковшовых экскаваторов / Т.3. Портной, Б.М. Парфёнов, А.И. Коган. - М.: Знак, 2002. $-113 c$.

2. Ключев В.И. Ограничение динамических нагрузок електропривода / В. И. Ключев. - М.:Энергия, 1971. $320 \mathrm{c}$.

3. Воскобойник В.Э. Основы электропривода производственных машин и комплексов: учебное пособие / В.Э. Воскобойник, В.А. Бородай - Д.: Государственный ВУЗ «НГУ», 2015. - $121 \mathrm{c}$.

4. Куиик А.С. Автоматизовані системи керування на програмованих логічних контролерах: Навч. посіб. Нач. ун-т «Львівська політехніка»/ А.С. Кучик, В.О. Місюренко.- Львів: Вид-во Львівської політехніки, 2011. $199 c$.

5. Тамарянський І.С., Єрмілова Н.В. Аналіз параметрів електропривода поворотної платформи екскаватора з урахуванням пружності системи // Збірник тез за матеріалами III Всеукраїнської науково-практичної Iнтернет-конференції «Електронні та мехатронні системи: теорія інноваиії, практика». (Полтава, 4 грудня 2017 р.) - Полтава: ПолтНТУ, 2017.

Надійшла до редколегії 27.12.2017

Рецензент: д-р техн. наук, проф. О.В. Козелков, Державний університет телекомунікацій, Київ.

\title{
МОДЕЛИРОВАНИЕ И ИССЛЕДОВАНИЕ ЭЛЕКТРОПРИВОДА ПОВОРОТНОЙ ПЛАТФОРМЫ ОДНОКОВШОВЫХ ЭКСКАВАТОРОВ
}

\author{
Н.В. Ермилова, Е.В. Гаврилко, С.Г. Кислица
}

В статье рассмотрено современное состояние и направления развития электропривода механизма поворота одноковшовых экскаваторов. Разработаны компьютерные модели систем автоматического управления для двух случаев: без учета и с учетом упругих свойств объекта. Проведенное моделирование системы позволило проанализировать динамические свойства электропривода экскаватора вместе с его механической частью и получить выводы о путях достижения наилучшей динамики системы.

Ключевые слова: электропривод экскаватора, поворотная платформа, упругость системы, компьютерная модель, автоматическое управление.

\section{MODELING AND RESEARCH OF THE ELECTRIC DRIVE OF THE ONE-BUCKET EXCAVATOR ROTARY PLATFORM}

N.V. Yermilova, E.V. Gavrilko, S.G. Kyslytsia

Modern state and directions of development of the electric drive the turning mechanism of one-bucket excavators are observed in the article. Computer models of automatic control systems are developed for two cases: without taking into account and with taking into account the elastic properties of the object. The simulation of the system gave the opportunity to analyze the dynamic properties of the excavator electric drive in combination with its mechanical part and obtain conclusions about the ways of achieving the best dynamics of the system.

Keywords: electric drive of the excavator, rotary platform, system elasticity, computer model, automatic control. 